\title{
Efficacy of adding mirabegron to alpha- adrenoreceptor blocker in patients with benign prostatic hyperplasia with persistent overactive bladder symptoms: A prospective study
}

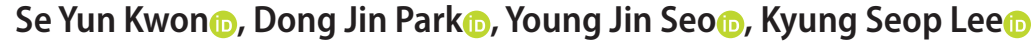 \\ Department of Urology, Dongguk University College of Medicine, Gyeongju, Korea
}

Purpose: To compare the efficacies of mirabegron $50 \mathrm{mg}$ addition after alpha-adrenoreceptor blocker in terms of reducing storage symptoms in patients with BPH.

Materials and Methods: Fifty-eight patients that had been taking alpha-adrenoreceptor blocker for more than 8 weeks, but had an OABSS of greater than 3 points, were initially enrolled. One group added any alpha-adrenoreceptor blocker with mirabegron 50 $\mathrm{mg}$ ( $\mathrm{n}=39$; the mirabegron group) and the other group received alpha-adrenoreceptor blocker only ( $\mathrm{n}=19$; the control group) for 8 weeks.

Results: In the control group, mean total IPSS decreased from 15.7 to 13.1 ( $p=0.298)$ and in mirabegron group, mean total IPSS decreased from 19.4 to 16.5 ( $p=0.024)$. Mean storage symptom scores reduced in the control and mirabegron groups from 8.5 to $7.9(p=0.584)$ and from 9.1 to $7.6(p=0.015)$, respectively, and mean QoL scores from 3.7 to $3.1(p=0.052)$ and 3.6 to $3.2(p=0.027)$, respectively. Mean overall OABSS in the control and mirabegron groups reduced from 8.4 to $7.2(p=0.173)$ and from 8.8 to 7.3 , respectively ( $p=0.005)$; mean OABSS Q3 from 3.6 to $2.9(p=0.073)$ and from 3.5 to $2.7(p=0.002)$, respectively; and mean OABSS Q4 from 2.4 to 2.0 ( $p=0.306)$ and from 2.7 to $2.0(p=0.016)$, respectively. The change of mean Qmax and PVR was insignificant in 2 groups.

Conclusions: IPSS total scores, storage symptom scores, QoL, overall OABSS, OABSS Q3 and Q4 were more improved significantly by alpha-adrenoreceptor blocker with mirabegron $50 \mathrm{mg}$ in BPH patients with persistent overactive symptoms. Mirabegron $50 \mathrm{mg}$ addition is considered to patients with persistent storage symptoms after alpha-adrenoreceptor blocker.

Keywords: Mirabegron; Prostatic hyperplasia; Urinary bladder, overactive

This is an Open Access article distributed under the terms of the Creative Commons Attribution Non-Commercial License (http://creativecommons.org/licenses/by-nc/4.0) which permits unrestricted non-commercial use, distribution, and reproduction in any medium, provided the original work is properly cited.

\section{INTRODUCTION}

Benign prostatic hyperplasia (BPH) is a common condition affecting most elderly men, and patients with $\mathrm{BPH}$ present with various lower urinary tract symptoms (LUTS). The main complaints of BPH patients are obstructive symptoms such as a weak urine stream and hesitancy, although a considerable number of patients also complain of storage

Received: 24 December, 2019 - Accepted: 3 March, 2020

Corresponding Author: Kyung Seop Lee (iD https://orcid.org/0000-0002-0554-4272

Department of Urology, Dongguk University College of Medicine, 87 Dongdae-ro, Gyeongju 38067, Korea

TEL: +82-54-770-8265, FAX: +82-54-770-8378, E-mail: ksleemd@dongguk.ac.kr 
symptoms [1,2].

Alpha-adrenoreceptor blockers play a major role in managing the obstructive symptoms of $\mathrm{BPH}$ and are considered the first-line treatment for moderate to severe LUTS [3,4]. In addition, various alpha-adrenoreceptor blockers have been reported to be effective at improving obstructive and storage symptoms [5,6]. However, irritating storage symptoms, which may be related to consistent detrusor overactivity or which may occur secondary to bladder outlet obstruction, may persist in some BPH patients [1,2]. Antimuscarinic agents have been added after an initial trial with alpha-adrenoreceptor blockers in BPH patients with persistent storage symptoms, despite historical concerns that patients with bladder outlet obstruction might experience urinary retention, and several non-placebo-controlled studies have demonstrated the efficacy and safety of this strategy $[7,8]$.

However, antimuscarinic agents have relatively high discontinuation rates. A systemic review of the literature published before 2010 revealed discontinuation rates of up to $31 \%$ in 12-week clinical trials and of up to $83 \%$ within 30 days in a medical claims study [9]. Dry mouth, the most commonly reported adverse effect, is often cited as the reason for discontinuation, although antimuscarinic agents are associated with high frequencies of adverse effects such as constipation and blurred vision [10,11].

In contrast, mirabegron can be used in patients who respond poorly to alpha-adrenoreceptor blockers or are unable to tolerate antimuscarinic agents. The incidences of adverse effects of mirabegron are similar or low compared with antimuscarinic agents. In addition, several studies have concluded that symptom improvement in $\mathrm{BPH}$ is more likely for mirabegron [12,13], and recently, antimuscarinic agents are being replaced by mirabegron in a combination setting. However, few studies have addressed combinatorial treatment with mirabegron and alpha-adrenoreceptor blockers in $\mathrm{BPH}$ with persistent overactive symptoms [14].

In the present study, we investigated the efficacy of adding $50 \mathrm{mg}$ mirabegron in patients with $\mathrm{BPH}$ with persistent overactive symptoms after treatment with an alpha-adrenoreceptor blocker.

\section{MATERIALS AND METHODS}

We collected and analyzed data from patients with BPH who complained of LUTS between January 2018 and December 2018. This prospective randomized study was conducted at our hospital and was approved by the Dongguk University Gyeongju Hospital Institutional Review Board before data retrieval and analysis (approval number: 110757-
201602-HR-05-03). All participants were new outpatients and received an informed consent form for the study. Laboratory analyses were performed at baseline before the study began and included urinalysis and liver and kidney function tests. In addition, the International Prostate Symptom Score (IPSS), Overactive Bladder Symptom Score (OABSS), maximal flow rate (Qmax), postvoid residual volume (PVR), and prostate volumes (determined by transrectal ultrasound) were recorded. After a 1-week washout period, the IPSS, OABSS, Qmax, and PVR were reassessed and patients were divided into two groups: an alpha-adrenoreceptor blocker only group and an alpha-adrenoreceptor blocker with mirabegron group. Fifty-eight patients were enrolled and assigned to the two groups by use of a random number generator. The patients had been taking an alpha-adrenoreceptor blocker for more than 8 weeks and their overall OABSS was over three points. In particular, the OABSS on question 3 (Q3) exceeded two points. Nineteen patients were treated with alpha-adrenoreceptor blocker only for 8 weeks (the control group), and 39 patients were treated with alpha-adrenoreceptor blocker plus mirabegron for 8 weeks (the mirabegron group). After the 8-week treatment period, total IPSS, IPSS storage symptom subscores, overall OABSS, OABSS on Q3, OABSS on Q4, Qmax, and PVR were recorded (Fig. 1).

Patients treated with 5-alpha-reductase inhibitors within 6 months of study entry, patients treated with antimuscarinic agents within 8 weeks, patients aged less than 40 years, patients with a lower overall OABSS than before treatment, patients with liver (an aspartate aminotransferase/alanine aminotransferase ratio >100 IU/L) or kidney function (creatinine $>2 \mathrm{mg} / \mathrm{dL}$ ) findings or abnormal urinalysis (red blood cell $>5 /$ high power field [HPF], white blood cell $>5 / \mathrm{HPF}$ ) findings, and patients who developed a severe adverse effect, such as an allergic reaction or orthotropic hypotension, were excluded during alpha-adrenoreceptor blocker treatment.

We compared continuous variables using the paired t-test and categorical variables using the Wilcoxon signed rank test. All $\mathrm{p}$-values were two-sided and $\mathrm{p}$-values with $\mathrm{p}<0.05$ were considered significant. Analysis was by use of SPSS ver. 18.0 (PASW Statistics; IBM Corp., Armonk, NY, USA).

\section{RESULTS}

Mean patient ages in the control and mirabegron groups were $71.7 \pm 7.1$ and $69.8 \pm 7.0$ years, respectively. Mean prostate volumes in the two groups were $30.5 \pm 14.0$ and $30.3 \pm 8.7 \mathrm{~mL}$, respectively. Baseline characteristics were not significantly different between the two groups (Table 1). After the 8-week treatment period, the mean total IPSS decreased from 15.7 


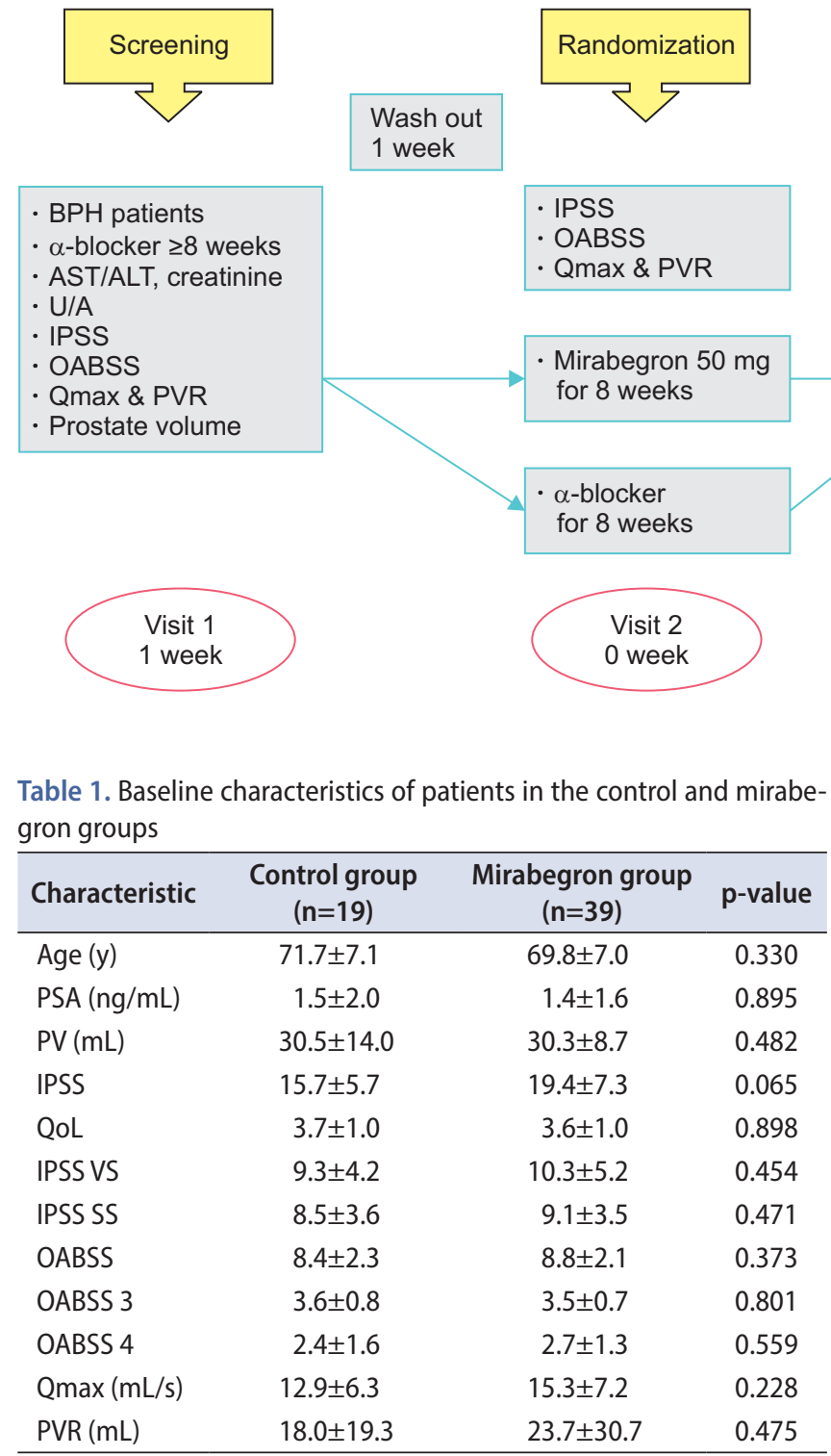

Values are presented as mean \pm standard deviation.

PSA, prostate-specific antigen; PV, prostate volume; IPSS, International Prostate Symptom Score; QoL, quality of life; VS, voiding symptom subscore; SS, storage symptom subscore; OABSS, Overactive Bladder Symptom Score; Qmax, maximal flow rate; PVR, postvoid residual volume.

to $13.1(\mathrm{p}=0.298)$ in the control group and from 19.4 to 16.5 $(p=0.024)$ in the mirabegron group. Mean IPSS storage symptom subscores decreased in the control and mirabegron groups from 8.5 to $7.9(p=0.584)$ and from 9.1 to $7.6(p=0.015)$, respectively, and the mean quality of life (QoL) subscore decreased from 3.7 to $3.1(\mathrm{p}=0.052)$ and from 3.6 to $3.2(\mathrm{p}=0.027)$, respectively (Fig. 2). The mean overall OABSS in the control and mirabegron groups decreased from 8.4 to $7.2(p=0.173)$ and from 8.8 to $7.3(\mathrm{p}=0.005)$, respectively. The mean OABSS on Q3 decreased from 3.6 to 2.9 ( $\mathrm{p}=0.073$ ) and from 3.5 to 2.7 ( $\mathrm{p}=0.002$ ), respectively, and the mean OABSS on Q4 de- creased from 2.4 to $2.0(\mathrm{p}=0.306)$ and from 2.7 to $2.0(\mathrm{p}=0.016)$ (Fig. 3), respectively. Mean Qmax changed in the control and mirabegron groups from 12.9 to $14.2 \mathrm{~mL} / \mathrm{s}(\mathrm{p}=0.308)$ and from 15.3 to $14.9 \mathrm{~mL} / \mathrm{s}(\mathrm{p}=0.749)$, and mean PVR increased from 18.0 to $20.6 \mathrm{~mL}(\mathrm{p}=0.472)$ and from 23.7 to $42.9 \mathrm{~mL}(\mathrm{p}=0.581)$, respectively, but this intergroup difference was not significant.

Complication rates did not differ statistically in the control and mirabegron groups ( $16.7 \%$ vs. $13.2 \%, p=0.726)$. There was one case of dizziness, one case of headache, and one case of nasal stuffiness in the control group, and two cases of indigestion, two cases of dizziness, and one case of headache in the mirabegron group.

\section{DISCUSSION}

LUTS are one of the most common clinical symptoms in patients with BPH [15]. LUTS can distinguish between storage and obstructive symptoms, but the incidence rates of these two symptoms are similar and overlap [16]

Alpha-adrenoreceptor blockers are generally used a firstline treatment for mild to moderately bothersome BPHLUTS. Alpha-adrenoreceptor blockers are also known to improve storage symptoms related to bladder outlet obstruction. Moreover, detrusor overactivity has been identified in $45 \%$ to $50 \%$ of men with $\mathrm{BPH}$ and this percentage increases with the severity of obstruction [17-19]. For these patients, the benefits of antimuscarinic agents in an add-on setting have been well documented in several randomized studies [7,20-22]. Therefore, antimuscarinic agents, which were traditionally contraindicated because of the fear of precipitating acute urinary retention, can be safely administered 

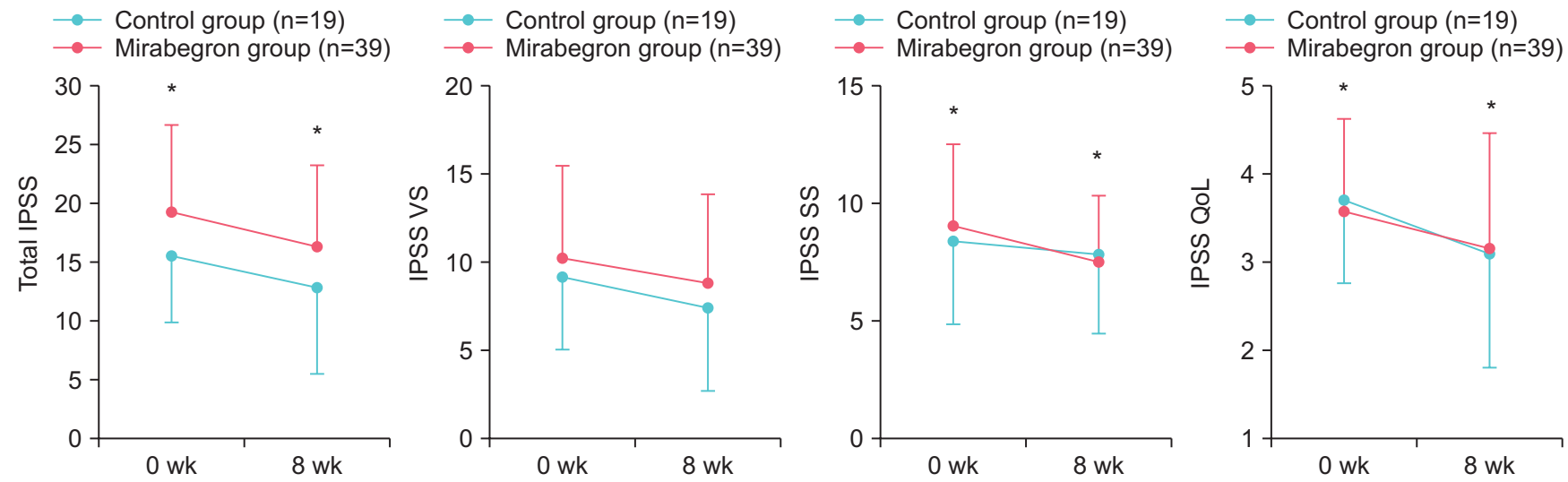

Fig. 2. Changes in total IPSS, IPSS VS, IPSS SS, and QoL in both groups. IPSS, International Prostate Symptom Score; VS, voiding symptom subscore; SS, storage symptom subscore; QoL, quality of life score. ${ }^{*} \mathrm{p}<0.05$.
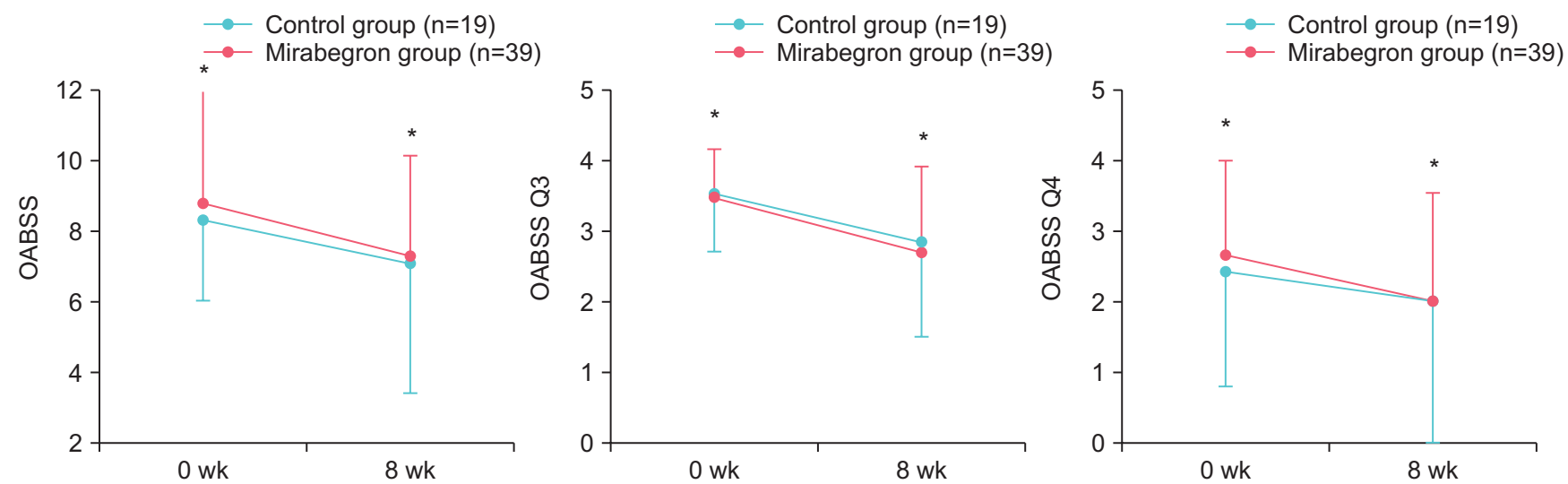

Fig. 3. Changes in OABSS on Q3 and Q4 in both groups. OABSS, Overactive Bladder Symptom Score; Q3, question 3; Q4, question 4. *p<0.05.

at recently recommended doses to most patients with $\mathrm{BPH}$. However, systemic blockade of muscarinic receptors leads to common, bothersome adverse events such as dry mouth, constipation, and headache [10,11]. Mirabegron is a selective $\beta 3$-adrenoceptor agonist and provides an alternative treatment option with established efficacy in patients with overactive bladder symptoms [23,24]. Overall, mirabegron-related rates of treatment-emergent adverse events are similar to those observed for antimuscarinics [25], but the risks for dry mouth and constipation are significantly higher than with mirabegron. However, the therapeutic effects of combined alpha-adrenoreceptor blocker and mirabegron are not well known, and no report has been issued on the topic in Korea.

Lee et al. [7] compared doxazosin with or without tolterodine in 144 patients with symptomatic bladder outlet obstruction and an overactive bladder. In patients with no improvement after 3 months of treatment with doxazosin, $37 \%$ with bladder outlet obstruction and $73 \%$ with bladder outlet obstruction and overactive bladder improved after the addition of tolterodine to their medication regimen. Acute urinary retention developed in $3.3 \%$ of the patients treated with the combined therapy. Recently, Ichihara et al. [14] conducted the first randomized controlled study to address the efficacy of combined alpha-adrenoreceptor blocker and 33 adrenoceptor agonist in patients with bladder outlet obstruction and overactive bladder. The change in overall OABSS during the treatment period was significantly greater in the combination group than in the monotherapy group. Furthermore, changes in urinary urgency scores, daytime frequencies, IPSS storage symptom subscores, and QoL indexes at 8 weeks were significantly greater in the combination group, and PVR was significantly greater in the combination group.

Safety is another important aspect of the management of male LUTS. In the present study, three types of adverse events were reported in seven patients: dry mouth in three patients, constipation in two patients, and headache in patients. However, no patient discontinued their medication and no adverse events associated with urinary retention occurred.

Ichihara et al. [14] reported that $13.9 \%$ in the mirabegron add-on group experienced adverse events identified as consti- 
pation, acute urinary retention, increased urgency, dizziness, or heartburn, each of which occurred in one patient, and increased hepatic enzymes, which occurred in one patient. Of these patients, $83.3 \%$ stopped taking mirabegron owing to the adverse events.

This study had some limitations that should be considered. It was performed on a relatively small sample and had an open label and not a placebo-controlled design and short treatment period. Nevertheless, it was conducted using a prospective design and is the first comparative study to be performed on alpha-adrenoreceptor blocker and mirabegron in Korean patients with $\mathrm{BPH}$.

\section{CONCLUSIONS}

Add-on mirabegron after alpha-adrenoreceptor blocker was found to be more effective than alpha-adrenoreceptor blocker monotherapy in patients with $\mathrm{BPH}$ with persistent overactive bladder symptoms. Add-on mirabegron improved the total IPSS, storage symptom subscore, overall OABSS, OABSS on Q3, OABSS on Q4, and QoL without urinary retention or severe adverse effects.

\section{CONFLICTS OF INTEREST}

The authors have nothing to disclose.

\section{AUTHORS' CONTRIBUTIONS}

Research conception and design: Kyung Seop Lee. Data acquisition: Young Jin Seo. Statistical analysis: Dong Jin Park. Data analysis and interpretation: Se Yun Kwon. Drafting of the manuscript: Se Yun Kwon. Critical revision of the manuscript: Kyung Seop Lee and Se Yun Kwon. Obtaining funding: no fund. Administrative, technical, or material support: Se Yun Kwon. Supervision: Kyung Seop Lee. Approval of the final manuscript: Kyung Seop Lee.

\section{REFERENCES}

1. Chapple CR, Roehrborn CG. A shifted paradigm for the further understanding, evaluation, and treatment of lower urinary tract symptoms in men: focus on the bladder. Eur Urol 2006;49:651-8.

2. Lemack GE. Defining the role of overactive bladder treatments in men with lower urinary tract symptoms. Nat Clin Pract Urol 2007;4:174-5.

3. McVary KT, Roehrborn CG, Avins AL, Barry MJ, Bruskewitz RC, Donnell RF, et al. Update on AUA guideline on the man- agement of benign prostatic hyperplasia. J Urol 2011;185:1793803.

4. Oelke M, Bachmann A, Descazeaud A, Emberton M, Gravas S, Michel MC, et al. EAU guidelines on the treatment and followup of non-neurogenic male lower urinary tract symptoms including benign prostatic obstruction. Eur Urol 2013;64:118-40.

5. Chapple CR, Montorsi F, Tammela TL, Wirth M, Koldewijn E, Fernández Fernández E. Silodosin therapy for lower urinary tract symptoms in men with suspected benign prostatic hyperplasia: results of an international, randomized, double-blind, placebo- and active-controlled clinical trial performed in Europe. Eur Urol 2011;59:342-52.

6. Hwang EC, Gandhi S, Jung JH, Imamura M, Kim MH, Pang R, et al. Naftopidil for the treatment of lower urinary tract symptoms compatible with benign prostatic hyperplasia. Cochrane Database Syst Rev 2018;10:CD007360.

7. Lee JY, Kim HW, Lee SJ, Koh JS, Suh HJ, Chancellor MB. Comparison of doxazosin with or without tolterodine in men with symptomatic bladder outlet obstruction and an overactive bladder. BJU Int 2004;94:817-20.

8. Kaplan SA, He W, Koltun WD, Cummings J, Schneider T, Fakhoury A. Solifenacin plus tamsulosin combination treatment in men with lower urinary tract symptoms and bladder outlet obstruction: a randomized controlled trial. Eur Urol 2013;63:15865.

9. Sexton CC, Notte SM, Maroulis C, Dmochowski RR, Cardozo L, Subramanian D, et al. Persistence and adherence in the treatment of overactive bladder syndrome with anticholinergic therapy: a systematic review of the literature. Int J Clin Pract 2011;65:567-85.

10. Rudy D, Cline K, Harris R, Goldberg K, Dmochowski R. Time to onset of improvement in symptoms of overactive bladder using antimuscarinic treatment. BJU Int 2006;97:540-6.

11. Blake-James BT, Rashidian A, Ikeda Y, Emberton M. The role of anticholinergics in men with lower urinary tract symptoms suggestive of benign prostatic hyperplasia: a systematic review and meta-analysis. BJU Int 2007;99:85-96.

12. Chapple CR, Nazir J, Hakimi Z, Bowditch S, Fatoye F, Guelfucci F, et al. Persistence and adherence with mirabegron versus antimuscarinic agents in patients with overactive bladder: a retrospective observational study in UK clinical practice. Eur Urol 2017;72:389-99.

13. Sebastianelli A, Russo GI, Kaplan SA, McVary KT, Moncada I, Gravas S, et al. Systematic review and meta-analysis on the efficacy and tolerability of mirabegron for the treatment of storage lower urinary tract symptoms/overactive bladder: comparison with placebo and tolterodine. Int J Urol 2018;25:196-205.

14. Ichihara K, Masumori N, Fukuta F, Tsukamoto T, Iwasawa A, Tanaka Y. A randomized controlled study of the efficacy of 
tamsulosin monotherapy and its combination with mirabegron for overactive bladder induced by benign prostatic obstruction. J Urol 2015;193:921-6.

15. Madersbacher S, Haidinger G, Temml C, Schmidbauer CP. Prevalence of lower urinary tract symptoms in Austria as assessed by an open survey of 2,096 men. Eur Urol 1998;34:13641.

16. Blaivas JG. Obstructive uropathy in the male. Urol Clin North Am 1996;23:373-84.

17. Brading AF, Turner WH. The unstable bladder: towards a common mechanism. Br J Urol 1994;73:3-8.

18. Leppanen MK. A cystometric study of the function of the urinary bladder in prostatic patients. Urol Int 1962;14:226-38.

19. Price DA, Ramsden PD, Stobbart D. The unstable bladder and prostatectomy. Br J Urol 1980;52:529-31.

20. Chapple C, Herschorn S, Abrams P, Sun F, Brodsky M, Guan Z. Tolterodine treatment improves storage symptoms suggestive of overactive bladder in men treated with alpha-blockers. Eur Urol 2009;56:534-41.

21. Kaplan SA, McCammon K, Fincher R, Fakhoury A, He W. Safety and tolerability of solifenacin add-on therapy to alphablocker treated men with residual urgency and frequency. J Urol 2009;182:2825-30.
22. Yamaguchi O, Kakizaki H, Homma Y, Takeda M, Nishizawa $\mathrm{O}$, Gotoh M, et al. Solifenacin as add-on therapy for overactive bladder symptoms in men treated for lower urinary tract symptoms--ASSIST, randomized controlled study. Urology 2011;78:126-33.

23. Khullar V, Amarenco G, Angulo JC, Cambronero J, Høye K, Milsom I, et al. Efficacy and tolerability of mirabegron, a $\beta(3)$ adrenoceptor agonist, in patients with overactive bladder: results from a randomised European-Australian phase 3 trial. Eur Urol 2013;63:283-95.

24. Herschorn S, Barkin J, Castro-Diaz D, Frankel JM, EspunaPons M, Gousse AE, et al. A phase III, randomized, doubleblind, parallel-group, placebo-controlled, multicentre study to assess the efficacy and safety of the $\beta_{3}$ adrenoceptor agonist, mirabegron, in patients with symptoms of overactive bladder. Urology 2013;82:313-20.

25. Nitti VW, Chapple CR, Walters C, Blauwet MB, Herschorn S, Milsom I, et al. Safety and tolerability of the $\beta 3$-adrenoceptor agonist mirabegron, for the treatment of overactive bladder: results of a prospective pooled analysis of three 12-week randomised Phase III trials and of a 1-year randomised Phase III trial. Int J Clin Pract 2014;68:972-85. 